\title{
Reform on Personnel Training Mode for Primary Education Specialty Based on Standard
}

\author{
Jun Yang \\ School of Education and Sports, Bohai University, Jinzhou, 121013, China \\ yj690213@126.com
}

Keywords: primary education specialty; personnel training mode; primary school teachers; professional standard; teaching reform

\begin{abstract}
To deepen the reform of the personnel training mode, explore the advanced concept and structure optimization of talent training mode have become an important issue in the primary education specialty. In this paper, we study the reform content, reform objectives and training programs. Reform from the aspects of the concept of running a school, the construction of the curriculum system, the training mode, the practice system and the talent evaluation method; To achieve the multi-level personnel training objectives of scientific thinking with employment and entrepreneurship oriented , good practice, and innovating; We should set up special training program with the concept of "integration" education, "diversification" training target, "division" personnel training, "mode" course setting, "situation" teaching mode, "whole course" teaching practice, "process" academic evaluation, "system" quality cultivation.
\end{abstract}

\section{Introduction}

Studying for primary education major students in normal colleges and universities, the students are given priority to receive general education, after entering the University, knowledge system of learning and education research training more than the cultivation of practice ability and talent, "elementary school teachers" professional characteristics and special demand is weakening. In the face of the challenge of the transformation of primary education in primary education, and the challenges brought by the social transformation, it is urgent to explore a way to reform the training mode of primary education in the times of development and social needs. Bohai university of primary education undergraduate professional began enrollment since 2001, and achieved greater development. College of continuous reporting and access to the reform of Liaoning Province, primary education undergraduate training program after four years of a round of undergraduate experimental teaching, in the grasp of integrated training and development of rectangular area, and accumulated a certain experience in running a school [1]. Take the Ministry of Education announced the primary school teachers professional standards as the basis, college should in-depth understanding of the professional characteristics of primary school teachers, in a wide range of research units, the basic level of the school, and gradually build a model for the reform of personnel training ideas.

\section{Research Status}

High quality teachers not only relate to the quality of teachers themselves, but also involves the whole process of teacher education. We take the outside data reference and field investigation in the province, information communication, through some investigation on teacher education talent cultivation pattern and teaching status, to analyze the research on teacher education personnel training mode of teaching reform and development trend.

The UIC teacher education curriculum in the United States is designed to take the talent cultivation as the core of the curriculum plan and curriculum objectives, curriculum structure and module division of the dual requirements of academic and teacher education, curriculum setting trend to give students more and more courses to choose freedom, practice teaching and other aspects of the construction of individual ability, in this view, we put forward that our country's 
teacher education curriculum should break the trend of the training objectives, strengthen the construction of teacher education curriculum, education curriculum and practical teaching. Through the reasonable construction of the curriculum system of teacher education, realize the characteristics of teacher education and teacher professional development [2].

From the point of view of development, the current teacher education in Normal University, and in the future, the need for innovative teachers education, the curriculum construction must be perfect. To change the fact that teachers' professional quality and teaching ability of teachers' professional quality and teaching ability is weak, the curriculum system should be changed from single to comprehensive, curriculum content from closed to open, and the curriculum objective from knowledge to teaching practice. The lacking teacher's power, the old teaching method, directly affects the improvement of the quality of primary school teachers [3].

In the primary school teachers' education and teaching status, there are a lot of problems: the content of the curriculum is aging, the proportion of "normal" and "academic" course is to be further scientific; compared with the curriculum reform of basic education, the lagging curriculum reform is far from being adapted to the requirements of the contemporary talent, the training plan is not advanced, the teaching mode, methods and ways are generally required to improve the problem of innovation; informatization and modernization composition teaching has lagged far behind in of the process of the development of the times [4]; educational practice of the single content and single form, it is difficult to meet the growth of new teachers from primary schools; fragmentation phenomenon exists in the teaching of primary school teacher education, and the lack of curriculum design, teaching design, teaching organization, professional accomplishment, the integration of classroom intelligence, and other factors. Academic discipline and the development of these disciplines are important, but professional discipline and its development are not; primary school teachers lack of independent development of the learning environment, there are many problems in the development of learner autonomy and so on [5].

In the face of the demand of high level teachers, we should change the present situation of the teacher education in higher normal colleges. Bohai university majoring in primary education is only a primary education undergraduate professional in western Liaoning province, with the advantages of area and industry. Compared with the normal school and college level elementary school students and elementary school students we should reflect their undergraduate advantages so as to have the core competitiveness: we not only should on the technological level of reserves of knowledge and teaching skills to develop other slightly better, more should show our advantage in the aspect of education and belief education ideal software. Only in this way, our school to primary education majors has outstanding professional characteristics.

\section{Reform Content}

After a wide range of professional project team discussed and demonstrated that the time is ripe for professional reform. In the past four years of professional reform, the establishment of the primary school education professional scientific, systematic and innovative personnel training mode reform system. Specific reform content as shown in Fig. 1.

\section{Reform Target}

Reform objectives include the following aspects:

(1) Flow of personnel training objectives from the "polarization" to "level". At present, there are two dimensions of the training mode of the primary education specialty in the primary school, which is to cultivate the students with theoretical and applicable students. This kind of thinking is lack of guidance, training, development and attention to the students' ability of self - employment. For example, the 2010 session of graduate student Zhaobaocheng, the primary school education professional, founded a ceramic company in Beijing and achieved initial success. These students' growth experience and development direction for us to develop new ideas, namely the use of elective module courses, to encourage students to personalize, diversified development, the 
establishment of a multi-level, multi angle, multi-level training mode of personnel training based on employment and entrepreneurship.

(2) The construction of curriculum system from the "win-win" to win "'. The aim of the reform of the professional course system is to train the students' service better. Here the "win-win" is ordered academic students and applicable students in the learning process can take what we need, can promote each other and flexible curriculum to achieve the conversion. But the curriculum system reform not only serves for the student's development, but also is the core question which the profession own development expands. Actively participate in "boutique" construction of teaching quality through the teaching reform, enhancing the overall primary education, professional construction and development level, so as to realize the teaching reform of the course from the "win-win" to "all-win".

(3) Teaching mode from "situation" to "panorama""'. Panoramic teaching is a teaching mode which is formed by the combination of case teaching and situational teaching. In this mode, to set up the real situation, and to the core of the teaching activities, to mobilize all the information resources in the teaching activities, to stimulate students' full awareness, the pursuit of the overall development of students' quality.

(4) Talent evaluation mode from "the entrance to the diversion of the selection" to the export care compensation". At present, our personnel training mode is only located in the entrance of the selection mechanism, and once the postgraduate entrance exam, how to qualified graduates to the identity of the social employment? This is a real problem that the educators have to face. To this end, the establishment of primary education in the "post postgraduate entrance examination" of the "compensation mechanism".

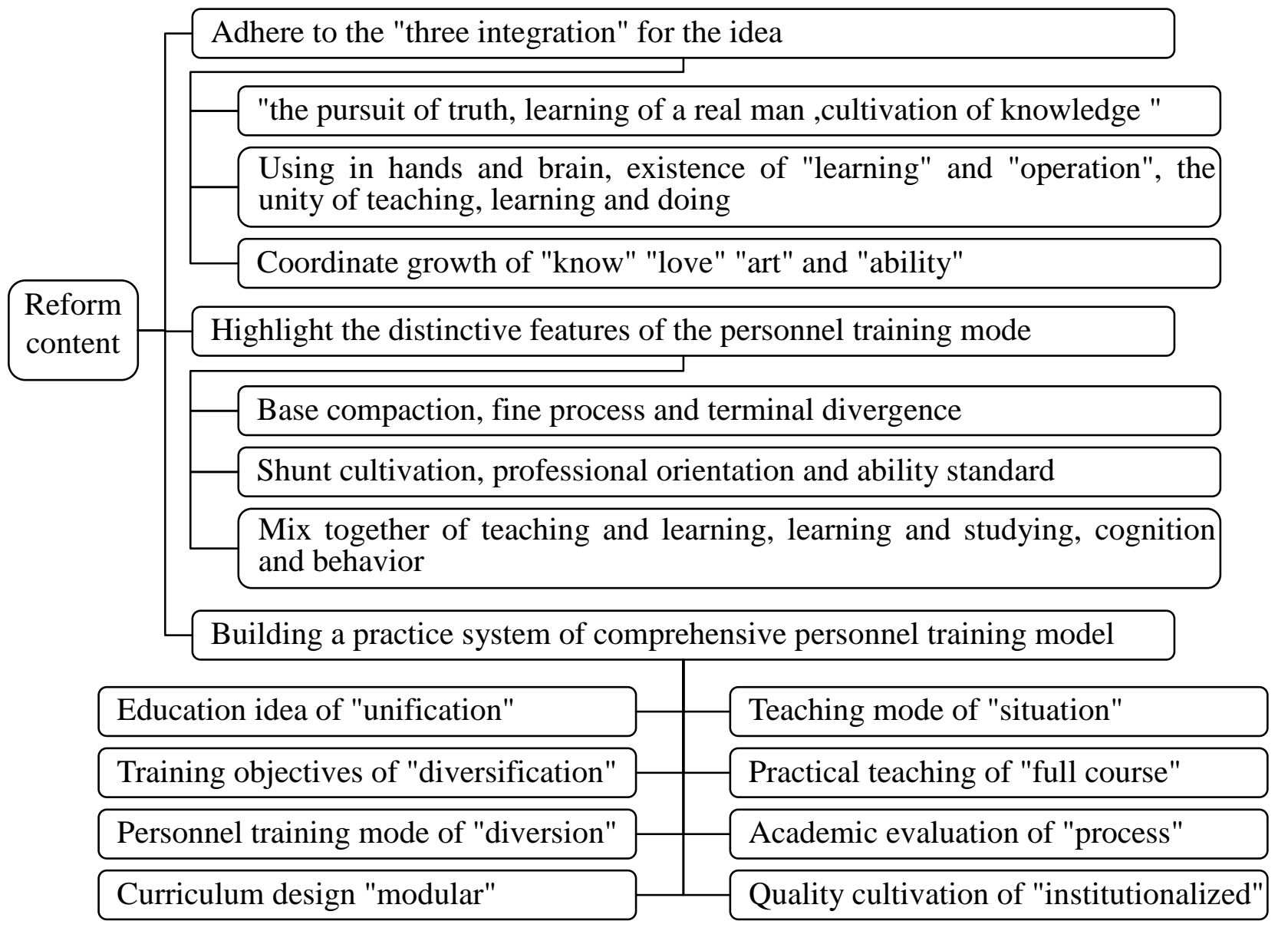

Fig. 1. Content on personnel training mode reform for primary education specialty

\section{Constructing Characteristic Training Scheme}

There are a lot of problems that need to be solved in the construction of professional development 
for a long time. The key problems are: the talent training mode and the development of economy and society are not connected, the curriculum and the teaching mode are not united, the practice teaching content is impractical. Facing these, we should deepen the reform of personnel training mode, explore the advanced and structural optimization of primary school teachers' training mode, on this basis, to build a training model with the professional training objectives.

(1) Education idea of "unification". Modern education ideas is modern teacher education not only to "person" to become "social professional", more important is to cultivate people to become a harmonious development of people. Therefore, in the professional development of primary education philosophy adhere to guide students to "the pursuit of truth, brilliant culture, learning to be a real man"; we should have both hands and brain, "learning" and "operation", the unity of knowledge; "know" "love" "art" and "ability" coordinated development of the philosophy of education.

(2) Training objectives of "diversification". Adhering to the concept of lifelong education, respect for the law of the development of the individual, to develop the academic theory of talents (such as the direction of education graduate students); down to cultivate the qualified personnel (qualified primary school teachers).

(3) Personnel training mode of "diversion". Primary school education in accordance with the school's "triage training" guidelines, combined with the law of the growth of teachers and the characteristics of primary school education to make a basic positioning:"One or two grade solidity and strengthen professional foundation to establish professional consciousness; three grade to carry out simulation training; grade four to enter the first line of actual combat".

(4) Curriculum design "modular". After extensive research, the primary education professional teaching team to develop a new training program, and ultimately based on the needs of the students to develop the training course for the modular design. This idea reflects the idea of curriculum reform of primary school teachers. There is a big difference between the application scheme and the academic program in the credit allocation. The application of the program is more important with credit in the field of professional qualification, practice, experiment and other aspects.

(5) Teaching mode of "situation". The situation of the teaching mode of the reform, the purpose is to pursue the effectiveness of professional teaching reform. For the practical students, the effectiveness is mainly reflected in the teaching to guide students to participate in teaching, inquiry teaching, cooperative teaching mode into the curriculum, learn to approach to the practice of teaching with "action research" in primary schools, students in the learning of knowledge and theory, through experience, participation, training their teaching practice. For academic students, the practical means of knowledge and theory of the system, focusing on the cultivation of their awareness and ability to explore the problem.

(6) Practical teaching of "full course". In the course of the development of primary school teachers teaching skills as the core, the creation of the primary school Chinese curriculum and teaching theory, primary school mathematics curriculum and teaching theory and other courses, set up a variety of simulation classroom, set up the humanities and arts activities room and science and Technology Education laboratory. The use of panoramic teaching, on-site diagnostic teaching, situational teaching methods to stimulate students' enthusiasm and interest.

(7) Academic evaluation of "process". In the professional reform, we pay attention to the process of evaluation, the results of the evaluation, exploration is conducive to students' diversified development which is conducive to the development of students' personality and conducive to the development of a variety of different ways of training students. In the course of educational theory and other educational theories, we gradually reduce the final assessment, emphasizing the process of assessment. The wide range of mechanical learning, surprise learning and to cope with the phenomenon of learning in the past can be corrected by the open and processing assessment.

(8) Quality cultivation of "institutionalized". First of all, we can give full play to the quality of the students and be the role of the teacher professional skills training in all of the quality of life in the daily activities of the students; Secondly, the primary school education major established the students' quality development, the writing skills, speech skills, class teacher work skills, modern 
education media and courseware production skills and access to education information skills are recorded to the growing file one by one, to standardize the evaluation of the training method, and the actual proof of the effectiveness of this training.

\section{Conclusion}

The college students majoring in education are the biggest beneficiaries of the research. Because of the advanced educational ideas, distinctive talent training mode and comprehensive practice teaching system, it can improve the performance of teachers' professional skills and knowledge, and have more competitiveness in the future. At the same time according to the situation of employment, can always enter the post higher levels of learning, and constantly improve the level of teachers' professional skills.

For all kinds of normal colleges, the research of this kind of characteristic training mode is the basis and accumulated practical experience for the establishment of normal education system. And can expand, optimize the school and social education resources, for the reform of China's teacher education reform will play a certain role in promoting. At the same time, the relationship between "normal" and "academic" in the curriculum system of normal university is made. The teaching objectives of different levels of various classes are determined, the reasonable curriculum development method and the method of curriculum setting are important. For the teachers' professional development and teaching reform has important guidance and promotion role. All kinds of basic education schools are the direct beneficiaries of the research results of this subject, because of the development of stronger practical ability and higher comprehensive quality of primary school teachers will promote the stable, sustained and healthy development of basic education.

\section{Acknowledgement}

This work is supported by A-class teaching reform project of Liaoning Education Department in 2014 (UPRP20140249),The key issue of Liaoning economic and social development in 2015 (2015lslktzimzs-02), A-class teaching reform project of Bohai University in 2013 (JG13YB004), "Twelfth Five Year" planning project of Liaoning education and science in 2013 (JG13CB030).

\section{References}

[1] J. F. Fang, "Evolution and Innovation: Teacher education in China and modern implicaton," Research in Educational Development, vol. 35, no. 6, pp. 18-23, 2014.

[2] A. Q. Li, "Characteristics and Enlightenment of American Teacher Education Curriculum: To USA Illinois University (UIC) teacher education courses as an example," Education Science, vol. 25, no. 3, pp. 34-37, 2009.

[3] X. M. Pan, "Research on the integration of teacher education curriculum and teaching reform," Journal of Qinghai Nationalities University (Education Science Edition), vol. 21, no. 1, pp. 47-49, 2011.

[4] X. M. Feng, "Study on the construction of the practical curriculum system of children literature in primary school education," Journal of Guilin Normal College, vol. 28, no. 4, pp. 55-58, 2014.

[5] Q. W. Chen, B. S. Zeng, "Training of primary school education in Oakland University in New Zealand and Its Enlightenment," Continue Education Research, vol. 30, no. 2, pp. 44-47, 2013.

[6] H. Y. Huang, "Conception of primary school education talents cultivation under the background of new curriculum reform," Forum on Contemporary Education, vol. 1, no. 12, pp. 56-60, 2007. 